\title{
"As Flies to Wanton Boys": Dilemmas and Dodging in the Field of Nonhuman Animal Ethics
}

\author{
Michael A. Ashby • Leigh E. Rich
}

Received: 22 September 2013 / Accepted: 23 October 2013

(C) Springer Science+Business Media Dordrecht 2013

On a daily basis, one of us (MA) drives around the Australian state of Tasmania where the "roadkill" bodies of native animals can be found everywhere, adding up to hundreds of thousands every year. Clearly, if these were humans, there would be an outcry! ${ }^{1}$ Initially, one may be saddened and even outraged to witness such public and unnatural deaths, but this tends to subside, becoming accepted as "unavoidable" and so invisible in plain sight, only to be revisited by anger, sorrow, and powerlessness again from time to time.

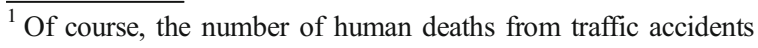
averages 1.3 million per year (Khazan 2013), to say nothing of life-altering injuries, and yet we in our modern world have come to accept this in terms of "low outrage" despite it being a "high hazard" public health problem. Perhaps it should not surprise us, then, that not only do we often disregard animal deaths on the streets but also incorporate "roadkill" into jokes and comedy routines, television and movie dialogue, and even cookbooks (see, e.g., Peterson 1987).
}

\section{A. Ashby}

Palliative Care Service, Royal Hobart Hospital, Southern Tasmania Area Health Service, and School of Medicine, Faculty of Health Sciences, University of Tasmania, 1st Floor, Peacock Building, Repatriation Centre, 90 Davey Street, Hobart, TAS 7000, Australia e-mail: michael.ashby@dhhs.tas.gov.au

\section{E. Rich $(\bowtie)$}

Department of Health Sciences (Public Health),

Armstrong Atlantic State University,

11935 Abercorn Street, Solms 201,

Savannah, GA 31419, USA

e-mail: leigh.rich@armstrong.edu
On the other side of the world, one of us (LER) dreams regularly of her childhood dog. Rather than buoyed by happy memories, she often awakens dismayed, not merely because the family pet has long since departed this world but because she regrets selfish decisions made in youth that today seem inexplicable. She's not sure why she relocated the dog's bed to the hallway after years of sharing a room or where she was when the dog was sprayed by a skunk and had to endure a traumatic tomato juice "shower" to mitigate the stench or how she could be absent when it was time to put the family friend "to sleep." There were, of course, many years of walks and tug-o'-war with toys and other ways of taking responsibility and showing care, but the dreams are a haunting reminder of the moral duty to "be better," to live a more virtuous and contemplative life even with regard to nonhumans.

Many of us live uneasily with animal suffering and death. Some of us are vegetarians and vegans, some advocate for research and products not tested on animals, some join environmental and animal rescue organizations. But for others this is just "collateral damage" on what is seen as the "dominant" human journey-a callous, hierarchical relationship akin to what Shakespeare wrote in King Lear to remind us of our own insignificant place: "As flies to wanton boys are we to th' gods./They kill us for their sport" (IV.i.36-37).

In this special issue of the Journal of Bioethical Inquiry, we revisit the area of "Nonhuman Animal Ethics" and what it means - morally - to be human in an interconnected, species-diverse world. How do we derive and sustain animal rights and improve, monitor, and regulate our 
individual and collective species behavior toward animals, in particular, and nature, in general, in an age of unprecedented and contested anthropogenic global environmental threat? After all, as some claim, are we not entitled to put ourselves first? (Although, we don't even do this very well, as we continue to put only some people first, leaving others just as forsaken as animals on the side of the road.)

But even for those of us who answer this question in the negative - that, no, we should not simply prioritize our own needs and desires and instead "love ... [a]ccording to [our] bond; no more nor less" (I.i.92-93)—we remain caught, like Lear's virtuous daughter Cordelia, in a no-win situation. The fate of the (animal) kingdom has become based on who can "heave/[one's] heart into [one's] mouth" most convincingly (I.i.91-92). As Joel Marks explains in "Animal Abolitionism Meets Moral Abolitionism: Cutting the Gordian Knot of Applied Ethics" (2013), the dialectic of normative ethics with regard to animals is too entrenched in the act of proclaiming and is, thus, continuously unproductive. Instead, Marks suggests cutting out the moral middleman (or elder daughters, as the case may be) and "see how this world goes with no eyes" (IV.vi.150-151) by relying on the rest of the "apparatus of ethics": "For even without recourse to morality it is still possible to advance arguments about what is true or false and even about what to do, and these arguments will have the great advantages over moral arguments of possibly being sound and likely being motivating" (Marks 2013, ๆ1 under “Amoral Animal Advocacy”).

For example, with regard to the question of eating meat, rather than stating an obscure premise such as "[u]nnecessary complicity in cruelty is wrong," his

"solution" is that less is more: Simply eliminate the moral premise ... and, really, cease to think in terms of an argument at all. Thus ...

Proposition 1. Eating meat in the modern world typically involves complicity in the cruel treatment of animals.

Proposition 2. For most people in the modern world it is unnecessary (for health and even for gustatory pleasure), and in many ways (health, environment, etc.) desirable not, to eat meat.

About the truth of these propositions one may surely debate and argue: adduce evidence, parse concepts, critique the design of an experiment or the logic of an inference, etc. But, unlike moral ones, the issues under discussion here are in theory resolvable (Marks 2013, $\uparrow 9$ and $\$ 12-\uparrow 15$ under “Amoral Animal Advocacy," emphasis original).

Likewise, Elisa Aaltola in "Skepticism, Empathy, and Animal Suffering" (2013) proposes that, instead of investigating the question of animal suffering from a skeptical approach that underscores human inability to "gain access to the subjective experiences of other animals" and thus a never-ending uncertainty about what goes on in animal minds, "empathy together with intersubjectivity be adopted" (Aaltola 2013, under "Abstract"). Empathy offers benefit over a scientific skepticism that will never be satisfied because, "[s]ignificantly, it is representational and not 'primordial,' which means that one does not have to experience what others experience (something more akin to 'emotional contagion'), but rather one can simply seek to perceive what that experience could be" (Aaltola 2013, $\mid 2$ under "Empathy and Intersubjectivity").

Both normative ethics and skepticism, then, "actually facilitate[] animal exploitation; for by default, so long as there is no final resolution of the dialectic, 'inertia' favors the current, exploitative practices" (Marks 2013, \10 under "Animal Ethics and Morality," emphasis original).

And "[w] hat would fill the void left by their removal," Marks asks, like a distressed King Lear naked and battered by a rude bioethical wind? "In two words: facts and feelings" (Marks 2013, $\$ 8$ under “The Dispensability of Morality").

In addition to the moral and scientific methodological dilemmas, the whole question of nonhuman animal ethics is riddled with emotion, culture, and history as well as the ambiguous and inconsistent daily behavior by most of us, like those who talk of and treat domesticated pets akin to children but still wear leather shoes and jackets or who contemplate the consequences of meat eating and industrialized food production but are still not vegan (like the philosopher of pioneering animal rights work, Peter Singer).

Are many of us, then, no better than Goneril or Regan, often professing one thing but doing another?

We also have divided the animal kingdom in perplexing ways. We could ask why animals are at once exemplary of suffering and at the same time eased from it by euthanasia (to the apparent envy of many humans), as evidenced in sayings such as "sick as a dog" and "you wouldn't let an animal suffer like that," or why pets are 
thought of in some situations as "family members" but in others as "objects of ownership." And why do some animals seem to be "more equal" than others?

Jessica Pierce in "The Dying Animal" (2013), for example, explores animal thanatology and this emerging field's implications for bioethics - what animals can teach us not only about themselves but also ourselves and the human condition - while Roger Scruton in "Our Love for Animals" (2013) and Melanie Rock and Chris Degeling in "Public Health Ethics and a Status for Pets as Person-Things" (2013) examine the place of animals and the paradoxes related to pet ownership in both rural and urban settings. The domesticated animal-human relationship is, of course, a complex one: The domestic dog has evolved with man for more than 30,000 years (with the ever-independent cat an unsurprising 12,000! [Zax 2007]) and companion animal grief is now a recognized entity and a cause of widespread human suffering, particularly among the elderly living alone. A new book entitled How Animals Grieve also explores the other half of the relationship, the issue of animal grief itself, once regarded as a nonsubject as animals were deemed not to have souls (see King 2013).

Finally, Jane Johnson in "Vulnerable Subjects? The Case of Nonhuman Animals in Experimentation" (2013) and Richard Twine in "Animals on Drugs: Understanding the Role of Pharmaceutical Companies in the Animal-Industrial Complex" (2013) offer insights into research animals and, in particular, the "limitations of the 3Rs/welfare approach currently adopted in the context of animal experimentation" that

fails to deliver for nonhuman animals in experimentation because it effectively addresses only one element of their vulnerability (inherent) and paradoxically through the institution of Animal Ethics Committees intended to protect experimental animals in fact generates new vulnerabilities that exacerbate their already precarious situation (Johnson 2013, under “Abstract”).

Thus, humans continue to demonstrably and, in certain ways presumably unarguably, value the lives of Homo sapiens more than those of nonhuman animals. But what are the reasons for this and, more importantly, the implications? Clearly, if we had to choose between running over a pet or a child, we would always avoid the child at the expense of the animal, and indeed it would be much more likely (although not unheard of) for a person to risk his or her own life more readily to rescue another human creature than something of a more fourfooted, winged, or flippered variety. And is it anthropomorphic romanticism or a scientifically discovered 98.3 percent sharing of genes that makes us more emotionally moved by baby gorillas than by ants, when in fact the insects are more imperative for our ecological survival than the great apes?

More significantly, should we take up the moral challenge and necessity of stewardship — of both living creatures and the ecosystems in which we all exist-for self-preservation or as a human duty in itself?

If we seek only our own safeguarding (a morally stunted approach at best), we become the brunt of a dull and interminable joke. Early settlers in "new worlds" such as Australia and the Americas would be bemused by the fact that what they initiated in the way of land clearance and hunting has within a few centuries led to the environmental devastation with which we now live. It surely would have seemed impossible to them (like some participants in modern environmental debates), given the vastness of buffalo-governed prairies and marsupial-filled grasslands. The unchartered territories were all just too big.

And, of course, there was another rationalizationGenesis 1:16: "Then God said: Let us make man in our image, after our likeness. And let them have dominion over the fish of the sea and over the birds of the heavens and over the livestock and over all the earth and over every creeping thing that creeps on earth."

So the justifications for much of human conduct with regard to nonhuman animals have been rooted either in some kind of "practical sovereignty" or in the "fact" that human beings are made in the image of God, the supposed key differentiating factor between humans and all other species. (Of course, every era seems to have its "key" distinction, whether it be using tools, using language, exhibiting culture, etc., each of which falls apart the more we learn of animals.) This type of "Great Chain of Being" thinking situates man as the true "moral primate" at the apex of a divinely given natural order of things from which can be rationalized almost any treatment of all those below.

How do we instead realize that this primacy, if it exists, does not mean that infliction of suffering or unjustified killing is consistent with ethics (Judeo-Christian or otherwise)? Perhaps we struggle enough with defining and promoting human dignity that to take on this task with nonhuman animals is no doubt more intellectually (and personally) daunting? 
It may, however, not be quite as hard as we think, as the papers in this issue of the $J B I$ illustrate, although there is still much work to do and cultural-industrialpolitical obstacles to overcome.

We already regularly recognize animals' natural "majesty" (recall the scene in the film The Queen in which Helen Mirren as Elizabeth II views with reverence and spiritual connection the corpse of a moose killed during a hunt $)^{2}$ and we speak often of it metaphorically ("magnificent beast," "king of the jungle," "big fish," "wise as an owl"). Children cross-culturally have an interest in animals, and it seems, with the abundance of animal-related documentaries, media channels, and viewing expeditions, so do many adults. This emotional, spiritual, and linguistic relationship with animals reflects humanity's admiration of nature as well as perhaps a modern yearning to reconnect with it from the techno-urbanized lifestyle in which increasingly large proportions of the world's population live, seemingly alienated from our Thoreau type of Waldenesque longings.

Embedded in the experience of being human, then, is an interest in "doing better" by other creatures who also inhabit the Earth.

And yet, from this position, we remain conflictedthinking we are beyond nature while desiring to return to it - and thus the fields of environmental and nonhuman animal ethics continue to be ripe for deeper intellectual exploration and greater multidisciplinary illumination. They are topics that go to the heart of the human situation and human responsibility in the broader natural order. But like the "very foolish fond old" Lear, we are still "doubtful" and "mainly ignorant/What place this is" (IV.vii.60-66). This is captured so uncomfortably eloquently by the words of another Englishman, Ted Hughes, whose poems exemplify our prevarication.

\footnotetext{
2 There is a mystical and primeval aspect of hunting that is often described by hunters throughout history. This is illustrated in the voice of the Emperor Hadrian as written by Marguerite Yourcenar in Memoirs of Hadrian (1963), where Hadrian's inner life is recreated by a 20th-century female writer who includes passages about the duel that any well-rounded classical ruler or warrior would have had with wild animals during the hunt, taking the hunter close to nature and, like soldiering, death. Of course, as many have argued, hunting may be unethical and, except in rare situations, wholly unnecessary, although some who disagree with hunting at times will grudgingly make exceptions for slain animals who are eaten and not "wasted." In other words, the kill and the resultant death are not just for sport.
}

When it comes to our nonhuman brethren, both our ambivalence and the contradictions (as identified in this special issue of the $J B I$ ) with which we struggle are revealed in the sight of a newly slaughtered swine, presumably in rural Yorkshire half a century or more ago. In the "View of a Pig," awe collides with the gritty reality of what we do to eat and survive, all underpinned by a soulfully deep hunger for natural connection:

The pig lay on a barrow dead.

It weighed, they said, as much as three men.

Its eyes closed, pink white eyelashes.

Its trotters stuck straight out.

Such weight and thick pink bulk

Set in death seemed not just dead.

It was less than lifeless, further off.

It was like a sack of wheat.

I thumped it without feeling remorse (Hughes 2003, 75).

\section{References}

Aaltola, E. 2013. Skepticism, empathy, and animal suffering. Journal of Bioethical Inquiry 10(4). doi:10.1007/s11673013-9481-4.

Hughes, T. 2003. Collected poems. Ed. P. Keegan. New York: Farrar, Straus and Giroux.

Johnson, J. 2013. Vulnerable subjects? The case of nonhuman animals in experimentation. Journal of Bioethical Inquiry 10(4). doi:10.1007/s11673-013-9473-4.

Khazan, O. 2013. A surprising map of countries that have the most traffic deaths. The Washington Post, January 18. http://www. washingtonpost.com/blogs/worldviews/wp/2013/01/18/asurprising-map-of-countries-that-have-the-most-trafficdeaths/.

King, B.J. 2013. How animals grieve. Chicago: The University of Chicago Press.

Marks, J. 2013. Animal abolitionism meets moral abolitionism: Cutting the Gordian knot of applied ethics. Journal of Bioethical Inquiry 10(4). doi:10.1007/s11673-013-9482-3.

Peterson, B.R. 1987. The original roadkill cookbook. Berkeley: Ten Speed Press.

Pierce, J. 2013. The dying animal. Journal of Bioethical Inquiry 10(4). doi:10.1007/s11673-013-9480-5.

Rock, M., and C. Degeling. 2013. Public health ethics and a status for pets as person-things: Revisiting the place of animals in urbanized societies. Journal of Bioethical Inquiry 10(4). doi:10.1007/s11673-013-9478-z.

Scruton, R. 2013. Our love for animals. Journal of Bioethical Inquiry 10(4). doi:10.1007/s11673-013-9477-0.

Twine, R. 2013. Animals on drugs: Understanding the role of pharmaceutical companies in the animal-industrial complex. 
Journal of Bioethical Inquiry 10(4). doi:10.1007/s11673013-9476-1.

Yourcenar, M. 1963. Memoirs of Hadrian. Trans. G. Frick. New York: Farrar, Straus and Giroux. Originally published as Mémoires d'Hadrien (Paris: Librairie Plon, 1951).
Zax, D. 2007. A brief history of house cats: It may be that "nobody owns a cat," but scientists now say the popular pet has lived with people for 12,000 years. Smithsonian, July 1 . http://www.smithsonianmag.com/history-archaeology/brief cats.html. 